\title{
Therapy preferences of patients with lung and colon cancer: a discrete choice experiment
}

\author{
This article was published in the following Dove Press journal: \\ Patient Preference and Adherence \\ 26 September 2017 \\ Number of times this article has been viewed
}

\author{
Katharina Schmidt ${ }^{1}$ \\ Kathrin Damm' \\ Arndt Vogel ${ }^{2}$ \\ Heiko Golpon ${ }^{3,4}$ \\ Michael P Manns ${ }^{2}$ \\ Tobias Welte $e^{3,4}$ \\ J-Matthias Graf von der \\ Schulenburg ${ }^{1,4}$ \\ 'Leibniz University of Hannover, \\ Center for Health Economics \\ Research (CHERH), Hannover, \\ Germany; ${ }^{2}$ Department of \\ Gastroenterology, Hepatology and \\ Endocrinology, Hannover Medical \\ School, Hannover, Germany; \\ ${ }^{3}$ Department of Pneumology, \\ Hannover Medical School, Hannover, \\ Germany; ${ }^{4}$ Biomedical Research \\ in Endstage and Obstructive Lung \\ Disease Hannover (BREATH), Member \\ of the German Center for Lung \\ Research (DZL), Hannover, Germany
}

Correspondence: Katharina Schmidt Leibniz Universität Hannover, Center for Health Economics Research Hannover (CHERH), Otto-Brenner-Str I, 30159 Hannover, Germany

Tel +49 5II 762 I7346

Fax +49 5II 762508 I

Email ks@cherh.de
Objectives: There is increasing interest in studies that examine patient preferences to measure health-related outcomes. Understanding patients' preferences can improve the treatment process and is particularly relevant for oncology. In this study, we aimed to identify the subgroup-specific treatment preferences of German patients with lung cancer (LC) or colorectal cancer (CRC).

Methods: Six discrete choice experiment (DCE) attributes were established on the basis of a systematic literature review and qualitative interviews. The DCE analyses comprised generalized linear mixed-effects model and latent class mixed logit model.

Results: The study cohort comprised 310 patients (194 with LC, 108 with CRC, 8 with both types of cancer) with a median age of $63(\mathrm{SD}=10.66)$ years. The generalized linear mixed-effects model showed a significant $(P<0.05)$ degree of association for all of the tested attributes. "Strongly increased life expectancy" was the attribute given the greatest weight by all patient groups. Using latent class mixed logit model analysis, we identified three classes of patients. Patients who were better informed tended to prefer a more balanced relationship between length and health-related quality of life (HRQoL) than those who were less informed. Class 2 (LC patients with low HRQoL who had undergone surgery) gave a very strong weighting to increased length of life. We deduced from Class 3 patients that those with a relatively good life expectancy (CRC compared with LC) gave a greater weight to moderate effects on HRQoL than to a longer life.

Conclusion: Overall survival was the most important attribute of therapy for patients with LC or CRC. Differences in treatment preferences between subgroups should be considered in regard to treatment and development of guidelines. Patients' preferences were not affected by sex or age, but were affected by the cancer type, HRQoL, surgery status, and the main source of information on the disease.

Keywords: patient preferences, lung cancer, colorectal cancer, Germany, latent class model, multi-criteria decision making

\section{Introduction}

In 2012, lung cancer (LC) and colorectal cancer (CRC) were two of the most common cancers worldwide. ${ }^{1}$ In developed countries, the 5-year survival rates of patients with CRC improved significantly between 1995 and 2009, ${ }^{2}$ whereas those of patients with LC showed only minor improvement. ${ }^{2}$ The aim of the World Health Organization 2013-2020 Global Action Plan is to reduce the rate of cancer mortality by improving service delivery through early diagnosis and enhanced screening programs. ${ }^{3}$ The prevalence of cancer will rise as a result of earlier detection of the disease; thus, the therapeutic options available will gain more attention.

Patients are often confronted with different therapeutic options, which may implicate severe adverse effects and uncertain outcomes. Typically, the patients evaluate therapeutic options in terms of their ability to prolong survival versus their 
expected effects on health-related quality of life (HRQoL). Consequently, it is important to know what patients prefer and what is most important to them during decision making. Previous studies have shown a discrepancy between the personal preferences of patients and the subjective assessments made by their physicians. ${ }^{4-9}$ However, we performed a systematic literature review which showed that, in general, patients do not wish to decide on their therapy personally and would prefer their physician to make the decision. ${ }^{10,11}$ Here, a conflict can occur, because the therapy that is provided to patients should be adjusted to meet their preferences regarding HRQoL and adverse effects. Previous studies on other diseases have shown that satisfaction with therapy can have a significant effect on disease outcomes and further treatment decisions. ${ }^{12-14}$ On the basis of these findings, patient preferences should be examined and integrated during decision making regarding cancer therapy.

Furthermore, patient preferences might influence political decisions regarding reimbursement for pharmaceuticals. In Germany, there is growing interest in preference measurement, following the introduction of the Act on the Reform of the Market for Medical Products (Arzneimittelneuordnungsgesetz [AMNOG]) in 2011. Although, according to the AMNOG, patient-reported outcomes should be taken into account during early evaluation of the benefits of new pharmaceuticals, ${ }^{15}$ patient preferences do not play an important role in Germany at present. The Federal Joint Committee (Gemeinsamer Bundesausschuss) has criticized the lack of quality in the scientific evaluations (dossiers) of pharmaceutical companies and overruled some patient-reported outcomes. ${ }^{16}$ Hence, our findings might influence the ongoing debate about the evidence provided by studies of patient preferences and be relevant to the German health care system.

The aim of the study was to examine the therapy preferences of German patients with LC and CRC. These two types of cancer show high prevalence rates in Germany and worldwide. However, their divergent overall survival rates and disease-related adverse effects might lead to different therapy preferences among patients with LC and CRC. In addition, we wanted to identify subgroups of patients that shared similar preferences, irrespective of the cancer type. Members of these homogenous subgroups might share same sex, age, or educational level. Comparison of the two different cancer types and the resulting patient (subgroupspecific) preferences represents the added value of our study. Consequently, our aim is to confirm the importance of patient preference studies and their need for implementation in health care. These data could also help physicians to make clinical decisions by differentiating among the preferences of various subgroups of patients and might enable improvement of therapy guidelines.

\section{Patients and methods Derivation of attributes and discrete choice tasks}

In a discrete choice experiment (DCE), two (or more) alternative scenarios are presented. Each alternative (profile) is described by several attributes. ${ }^{17}$ The participant must choose which of the profiles they prefer. ${ }^{18}$

The whole study process is illustrated in Supplementary material. First, we conducted a systematic literature review to identify the key topics related to cancer therapy for use in subsequent qualitative interviews. ${ }^{10,11}$ The systematic literature reviews identified 15 relevant studies of preferences with respect to therapy for $\mathrm{CRC}$ and 17 relevant studies of preferences with respect to therapy for LC. The most important concerns for patients with CRC were diarrhea, nausea, pain, requirement of a stoma, role functioning, emotional functioning, toxicity of chemotherapy, life expectancy/overall survival, and taking medication at home. ${ }^{10,11}$ For patients with LC, the most important concerns identified by the literature review were: fatigue, diarrhea, nausea, pain, role functioning, intensity of treatment, overall survival, and HRQoL versus length of life. ${ }^{10,11}$ Second, we conducted guided qualitative interviews that were based on the results of our systematic literature review. We interviewed 18 patients with LC and 17 patients with CRC, and then conducted content analyses (Aumann et $\mathrm{al}^{19}$ for interviews with LC patients and [Damm et al: Supplementary material] for interviews with CRC patients). We used the inductive and deductive categories from the content analysis to identify the main topics: adverse effects, social quality of life, emotional quality of life, and organization. Further subcategories (10-23) were established for each main topic. We sorted the identified categories on the basis of the frequency with which they were mentioned, separated by patients with LC and patients with CRC (Supplementary material). Subsequently, we chose the most frequently mentioned categories and determined whether they overlapped with respect to meaning. We aimed to cover a large spectrum of categories, while simultaneously ensuring minimal overlap or correlation between the attributes. To this end, we aggregated the categories into topics that could serve as attributes. Another restriction was the required total number of attributes (five to nine) to prevent overstraining of the interviewee. ${ }^{20}$ 
To generate the questionnaire, we identified five attributes from the most important categories that did not overlap in their meanings and added the attribute of overall survival from the literature review. We realized that the resulting attributes were similar for patients with CRC and those with LC. Therefore, we decided to use the same attributes for both groups of cancer patients. The first attribute that we examined was the efficacy of therapy, measured as additional life expectancy after diagnosis. Given that the time of survival can vary considerably between patients with CRC and those with $\mathrm{LC}$, we decided to examine the objective values rather than specific time periods. Adverse effects were separated into three attributes of "physical capacity", "appearance", and "food intake and digestion". Given this separation, we expected no overlaps between the attributes. The different possible levels assigned to the attributes were derived from the experiences of the interviewees and were divided into "minor", "medium", and "strong" effects. In the interviews, "physical capacity" was described as tiredness, decreased physical ability, and overall physical exhaustion. We carried these descriptions over into the questionnaire. The symptoms that were associated most commonly with "appearance" were hair loss, weight loss, and eczema. The fifth attribute identified was "waiting time in the clinic or therapy-associated practice". It corresponded to the time that patients had to spend waiting during therapy, for example, waiting time between blood tests and the start of chemotherapy. The final attribute referred to the provision of a "guide" who was independent and would provide information on the services and assistance associated with treatment for LC or CRC. During the interviews, the patients were highly critical of the treatment process and its organization. One of the more frustrating factors for the patients was the lack of information, rather than the waiting time itself, and more specifically, the strain that resulted from the lack of information on disease-associated proposals and paperwork. Some patients also mentioned that they had to coordinate communication between their doctors and their health insurance providers. Therefore, for the purpose of the questionnaire, we introduced the concept of a guide who would provide support for the patients either personally or over the telephone. This "guide" was defined as a free-of-charge service to reduce the effect of any monetary concerns that the patients might have. There were only two possible levels for this attribute: "yes" or "no". The final attributes and levels, including a description of the study participants, are presented in Table 1.

We used the Statistical Analysis Software \% ChoicEff macro to construct choice sets. ${ }^{21}$ We used two versions of
Table I Descriptions of attributes used in the questionnaire

\begin{tabular}{|c|c|c|}
\hline Attribute & & Levels \\
\hline Life expectancy & $\begin{array}{l}\text { Life expectancy at the time } \\
\text { of diagnosis with regard to } \\
\text { mean survival in patients } \\
\text { with lung or colon cancer } \\
\text { (average of all cancer stages) }\end{array}$ & $\begin{array}{l}\text { - Not increased } \\
\text { - Slightly increased } \\
\text { - Strongly increased }\end{array}$ \\
\hline $\begin{array}{l}\text { Physical } \\
\text { capacity }\end{array}$ & $\begin{array}{l}\text { Decrease in physical capacity } \\
\text { that influences everyday } \\
\text { life, for example, being out } \\
\text { of breath quickly, being } \\
\text { tired, sitting down often, or } \\
\text { sleeping during the day }\end{array}$ & $\begin{array}{l}\text { - Normal } \\
\text { - Moderately } \\
\text { decreased } \\
\text { - Strongly decreased }\end{array}$ \\
\hline Appearance & $\begin{array}{l}\text { Changes in appearance } \\
\text { caused by the disease itself } \\
\text { or the treatment (adverse } \\
\text { effects). Possible changes } \\
\text { include hair loss, eczema, } \\
\text { or weight loss }\end{array}$ & $\begin{array}{l}\text { - Unchanged } \\
\text { (no visible changes) } \\
\text { - Slightly changed } \\
\text { - Significantly changed }\end{array}$ \\
\hline $\begin{array}{l}\text { Food intake } \\
\text { and digestion }\end{array}$ & $\begin{array}{l}\text { Problems with food intake } \\
\text { or digestion, such as loss of } \\
\text { appetite, nausea, emesis, } \\
\text { or diarrhea }\end{array}$ & $\begin{array}{l}\text { - No problems/normal } \\
\text { - Minor problems } \\
\text { - Severe problems }\end{array}$ \\
\hline $\begin{array}{l}\text { Waiting time } \\
\text { (in the clinic) }\end{array}$ & $\begin{array}{l}\text { The time spent waiting } \\
\text { in the clinic or practice } \\
\text { for your therapy. This } \\
\text { could be, for example, } \\
\text { the waiting time between } \\
\text { blood tests and the start of } \\
\text { chemotherapy }\end{array}$ & $\begin{array}{l}\text { - No waiting time } \\
\text { - Moderate waiting } \\
\text { time } \\
\text { - Long waiting time }\end{array}$ \\
\hline
\end{tabular}

the questionnaire because blocking certain choice sets was found to reduce the burden on patients' decision making. The first choice set enabled us to test patients' understanding of the DCE method because it included a dominant profile. In total, we provided 10 choice sets of DCE tasks to each participant (for an example of choice set, see Supplementary material).

\section{Ethical standards}

The patients provided written informed consent to participate. Approval for this study was obtained from the ethics committee of the Hannover Medical School (Nr 1518-2012) and the Medical Association of Lower Saxony, the University of Goettingen, and the University Hospital Tuebingen.

\section{Development of the questionnaire}

We conducted a pretest to ensure that the final questionnaire could be understood easily by the patients. The pretest showed that most patients could not answer questions about their disease state or therapy goals (palliative, adjuvant, maintenance). Therefore, this question was excluded from 
the questionnaire because we were not allowed to access medical records.

The final questionnaire consisted of a section on patient information, a form regarding informed consent, a definition of the attributes, Likert-scale questions about the therapy attributes (from 1, "very unimportant" to 5, "very important"), 10 DCE sets, sociodemographic questions, and the cancer-specific HRQoL questionnaire developed by the European Organization for Research and Treatment of Cancer (EORTC), termed the EORTC QLQ-C3022,23 (for an overview of the variables, see Supplementary material).

\section{Study population}

Patients attending specialized ambulatory practices or the departments of pneumology or gastroenterology at eight hospitals in Germany were invited to participate in our study. The cooperating institutions were (for further information, see Supplementary material):

- Hannover Medical School, Department of Pneumology and Department of Gastroenterology, Hepatology and Endocrinology, Hannover;

- Johannes Wesling Medical Center, Department of Hematology, Oncology, Hemostaseology, and Palliative Care UKRUB, University of Bochum, Minden;

- Lung Cancer Center, Hospital Region Hannover;

- Clinic for Visceral, General, and Transplant Surgery, Surgical Study Center, University Hospital Tuebingen;

- Ambulatory Oncological Center, Hannover;

- Group Practice for Internal Medicine and Pulmonology, Celle;

- Interdisciplinary Short-term Oncology, Department of Hematology and Medical Oncology, Goettingen; and

- Group Practice for Hematology and Oncology, Hannover. The participating clinics administered the questionnaire to patients with LC and CRC of all disease stages who were aged $\geq 18$ years and had finished at least one cycle of chemotherapy (including in the past). Both modes of chemotherapy administration (tablet and infusion) were eligible for inclusion in the study.

In addition, we initiated an online survey with the same inclusion criteria. The link to the survey was distributed via the Facebook page of the German self-help organization ILCO, the Felix Burda Colon Cancer Website and Facebook page, the Center for Health Economics Research Hannover Facebook page, and the mailing lists of regional self-help groups for patients with CRC and LC.

The recruitment period was from September 2014 to October 2016. Neither patients nor physicians received any incentives for participating in the study. All participants provided informed consent. The minimum required sample size was 196, which was calculated in accordance with the study by de Bekker-Grob et al. ${ }^{24}$

Approval for the study was obtained from the ethics committees of the Hannover Medical School (reference number: 1518-2012), Medical Association of Lower Saxony, University of Goettingen, and University Hospital Tuebingen.

\section{Data analyses}

Following completion of the survey, we cleansed the data set (testing for impossible values, systematic missings, import errors, and so on) and calculated descriptive statistics for the variables (median, SD, percentages). The HRQoL was calculated using symptom scales, functional scales, and the global health score from the EORTC QLQ-C30 questionnaire. ${ }^{25}$ We applied logistic regression analyses to determine factors (independent variables) that influenced the choices made between the profiles of each choice set (dependent variables). The utility of each profile was calculated using Formula 1 in Supplementary material.

We used a generalized linear mixed-effects model (GLMM) to examine the effects of multiple answers for each individual choice set (serial_no). We calculated the GLMM for patients with CRC and LC separately, so that any differences between the two patient groups could be identified based on Hauber et $\mathrm{al}^{26}$ and McCulloch et $\mathrm{al}^{27}$ (Formula 2 in Supplementary material).

Finally, we used the latent class mixed logit model (LCMLM) with a different number of classes to identify, strictly on the basis of the data, possible sample subgroups with specific characteristics (eg, sociodemographic status, disease-specific parameters). These subgroup characteristics were presented in the so-called class-membership effects model. An overview of the variables tested for all models is provided in Supplementary material. The final model is shown in Formula 3 in Supplementary material.

The $\beta$-coefficients from the GLMM and LCMLM represent the weights of the utility for choosing the profile. $\beta$-coefficients $>0$ indicated that an attribute level was preferred, whereas coefficients $<0$ indicated that it was disfavored. Alternatively, coefficients $<0$ suggested that an attribute level was accepted in order to gain advantages in other attributes. The results for the $\beta$-coefficients were assumed to be significant at a $P$-value $\leq 0.05$.

The models were tested with different independent variables and, finally, lean models were targeted. Akaike and Bayesian information criteria were used to identify the model with the best fit for the data. All analyses were conducted 
with R statistics 3.1.2 (The R Foundation for Statistical Computing, Vienna, Austria), using the packages "Ime4" (for GLMM) and "lcmm" (for LCMLM).

\section{Results \\ Descriptive statistics}

In total, 369 patients participated initially in the study, but this number decreased to 310 participants after data cleansing. The distribution of mean age and sex did not differ significantly between the included and excluded groups of participants. Table 2 shows the characteristics of the patients. Given that only eight patients had both types of cancer, we did not assess their preferences separately.

The cohort was younger than the average ages of patients with LC and CRC in Germany. ${ }^{28,29}$ However, the general sex distribution of patients with LC and CRC in Germany was similar to that evident in our sample.

\section{Multivariate models}

\section{Generalized linear mixed-effects model}

Figure 1 shows the results of the three GLMMs (LC, CRC, full sample). A strong increase in life expectancy was the attribute level that was given the most weight by all three groups $\left(\beta_{\mathrm{LC}, \mathrm{OS} 2}=2.56, \beta_{\mathrm{CRC}, \mathrm{OS} 2}=1.77, \beta_{\text {ful }, \mathrm{OS} 2}=2.17\right.$; all $\left.P<0.001\right)$. For patients with LC, the level of "normal physical capacity" was given greater weight than a "moderate" or "strong decrease" in physical capacity $\left(\beta_{\mathrm{LC}, \mathrm{PC} 0}=0.79, \beta_{\mathrm{LC}, \mathrm{PC} 1}=0.34\right.$, $\left.\beta_{\mathrm{LC}, \mathrm{PC} 2}=-1.13 ; P<0.001\right)$. However, both the patients with CRC and the full sample rated "normal physical capacity" more highly than "moderately decreased capacity", although this was not statistically significant. With regard to "changes in appearance", all patient groups gave a greater weight to a "slightly changed appearance" than to an "unchanged appearance". "No problems" or "minor problems" with food intake and digestion were rated slightly higher by patients with LC than those with $\mathrm{CRC}\left(\beta_{\mathrm{LC}, \mathrm{FI} 0}=0.83, P<0.001 ; \beta_{\mathrm{CRC}, \mathrm{FI} 0}=0.49\right.$, $\left.P<0.001 ; \beta_{\mathrm{LC}, \mathrm{FI} 1}=0.18, P=0.05 ; \beta_{\mathrm{CRC}, \mathrm{FI} 1}=-0.14, P=0.15\right)$. "No waiting time" (reference category) was given slightly less weight by the full sample than by patients with $\mathrm{CRC}$ $\left(\beta_{\text {full,WT0 }}=0.25, \beta_{\mathrm{CRC}, \mathrm{WT} 0}=0.35 ; P<0.001\right)$. In general, the preferences of the three groups were very similar (see also Supplementary material).

\section{Latent class mixed logit model}

The LCMLM identified three different classes of patients with specific class-membership effects (Table 3; for a graphical presentation, see Supplementary material). The first class showed a strong preference for "clearly longer survival" $\left(\beta_{\mathrm{cl} 1, \mathrm{OS} 2}=1.56, P<0.001\right)$. In contrast, this class disfavored "slightly longer survival" $\left(\beta_{\mathrm{cl} 1, \mathrm{OS} 1}=-0.2, P<0.001\right)$. Patients in Class 1 accepted a "moderately decreased physical capacity" compared with a "normal physical capacity". In addition,

Table 2 Sample characteristics of included participants

\begin{tabular}{|c|c|c|c|c|}
\hline Characteristic & CRC & $\mathbf{L C}$ & Both & Total \\
\hline Sample size & 108 & 194 & 8 & 310 \\
\hline Sex & $49.6 \%$ men & $69.80 \%$ men & $40 \%$ men & $62.16 \%$ men \\
\hline Median age $(S D)$ in years & $59.5(12.66)$ & $63(10.58)$ & $48.5(8.90)$ & $63(10.66)$ \\
\hline \multicolumn{5}{|l|}{ Cancer type } \\
\hline CRC & $100 \%$ & $0 \%$ & $0 \%$ & $35.04 \%$ \\
\hline LC & $0 \%$ & $100 \%$ & $0 \%$ & $63.03 \%$ \\
\hline Both & $0 \%$ & $0 \%$ & $100 \%$ & $1.93 \%$ \\
\hline Median disease duration (SD) in years & $2(5.92)$ & I (2.14) & $7.5(7.20)$ & I (4.16) \\
\hline \multicolumn{5}{|l|}{ Marital status } \\
\hline Single & $8.6 \%$ & $10.0 \%$ & $0 \%$ & $9.3 \%$ \\
\hline Married & $69.6 \%$ & $70.3 \%$ & $80.0 \%$ & $70.2 \%$ \\
\hline Divorced & $13.2 \%$ & $13.9 \%$ & $0.2 \%$ & $13.8 \%$ \\
\hline Widowed & $8.6 \%$ & $5.7 \%$ & $0 \%$ & $6.6 \%$ \\
\hline \multicolumn{5}{|l|}{ School-leaving qualifications } \\
\hline None & $2.3 \%$ & $1.6 \%$ & $40.0 \%$ & $2.5 \%$ \\
\hline Primary school & $33.0 \%$ & $48.2 \%$ & $2.0 \%$ & $42.4 \%$ \\
\hline Secondary school & $34.1 \%$ & $30.0 \%$ & $40.0 \%$ & $31.6 \%$ \\
\hline High school & $30.7 \%$ & $20.1 \%$ & $0 \%$ & $23.4 \%$ \\
\hline \multicolumn{5}{|l|}{ Median global health status (SD) } \\
\hline Scale from 0 (worst) to 100 (best) & $66.7(22.69)$ & $58.3(20.44)$ & $58.3(20.56)$ & $66.7(21.56)$ \\
\hline \multicolumn{5}{|l|}{ Median HRQoL (SD) } \\
\hline Scale from I (very bad) to 7 (excellent) & $5(1.48)$ & $5(1.27)$ & $5(0.87)$ & $5(1.35)$ \\
\hline
\end{tabular}

Abbreviations: CRC, colorectal cancer; LC, lung cancer; HRQoL, health-related quality of life. 


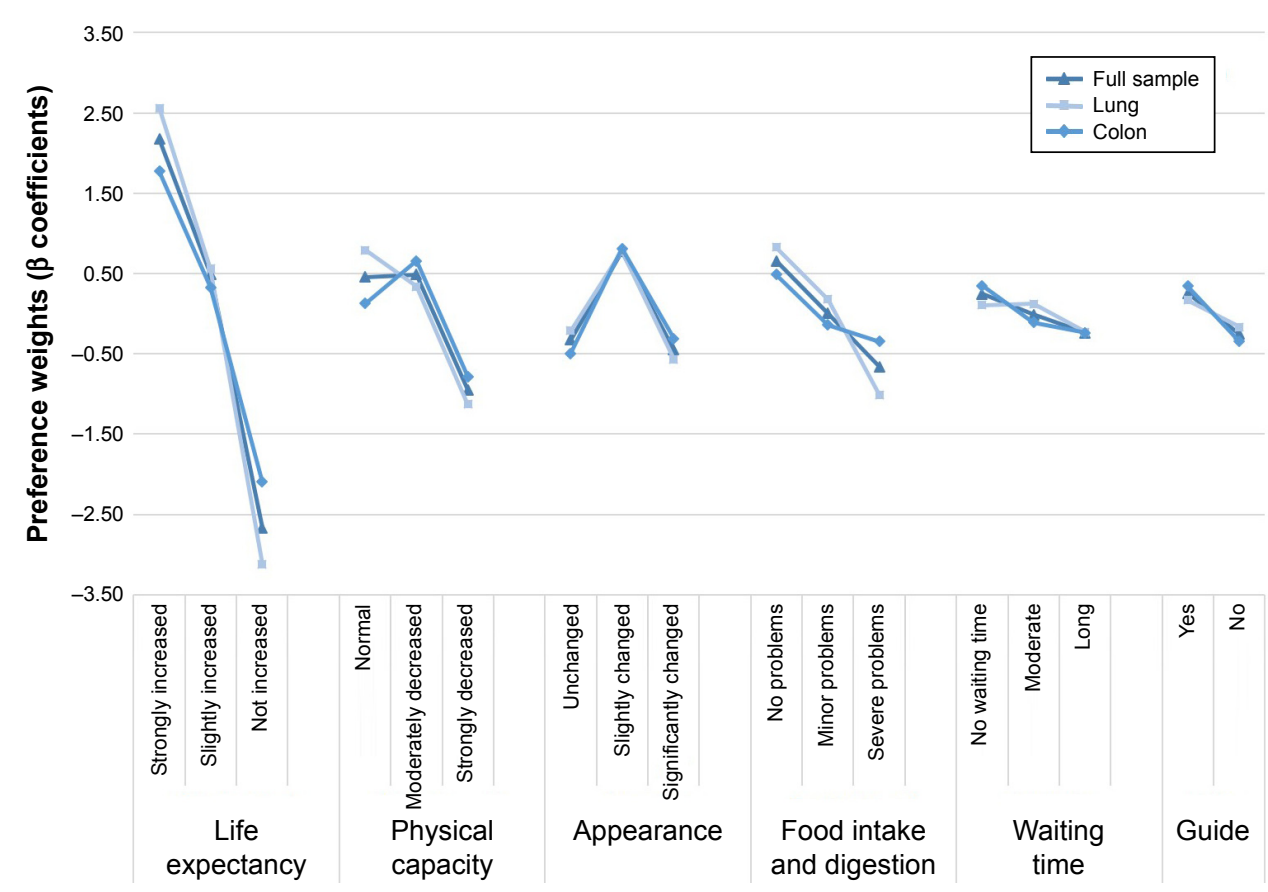

Figure I Results of mixed logit models.

Notes: Triangular shape, full sample; rectangular shape, lung cancer; diamond shape, colon cancer; random intercept: serial_no.

this class was willing to accept "moderate" and "long waiting times". Patients in Class 2 showed a preference for both "clearly longer" and "slightly longer survival" $\left(\beta_{\mathrm{cl} 2, \mathrm{os} 2}=0.64\right.$, $\left.\beta_{\mathrm{cl} 2, \mathrm{os} 1}=0.36 ; P<0.001\right)$. However, "physical capacity", "appearance", and "food intake and digestion" were also important attributes for this class. In this model, a decrease from "clearly longer" to "slightly longer survival" $\left(\beta_{\mathrm{OS} 2}\right.$ : $0.64-\beta_{\text {os } 1}: 0.36=0.28$ ) could be compensated for by a change from a "strong decrease" to a "moderate decrease" in physical capacity $\left(\beta_{\mathrm{PC} 2}:-0.66-\beta_{\mathrm{PC} 1}: 0.34=-1\right)$. Consequently, patients in Class 2 were willing to trade prolonged survival for smaller decreases in physical capacity. We cannot interpret the preferences of Class 3 in regard to "overall survival" because the results were not statistically significant $(P>0.05)$. This group

Table 3 Latent class mixed logit model results - attribute preferences

\begin{tabular}{|c|c|c|c|c|c|c|c|}
\hline \multirow[t]{2}{*}{ Attribute } & \multirow[t]{2}{*}{ Level } & \multicolumn{2}{|c|}{ Class I } & \multicolumn{2}{|c|}{ Class 2} & \multicolumn{2}{|c|}{ Class 3} \\
\hline & & $\beta_{\mathrm{cll}}$ & $P$-value & $\beta_{\mathrm{cl} 2}$ & $P$-value & $\beta_{\mathrm{cl3}}$ & $P$-value \\
\hline Intercept & & ne & & 0.07 & & 0.05 & \\
\hline \multirow[t]{3}{*}{ Overall survival } & Clearly longer & 1.56 & 0.00 & 0.64 & 0.00 & 0.07 & 0.27 \\
\hline & Slightly longer & -0.20 & 0.00 & 0.36 & 0.00 & 0.07 & 0.33 \\
\hline & Not longer (ref) & -1.36 & & -1.00 & & -0.14 & \\
\hline \multirow[t]{3}{*}{ Physical capacity } & Normal & 0.08 & 0.02 & 0.32 & 0.00 & -0.49 & 0.00 \\
\hline & Moderate decrease & 0.28 & 0.00 & 0.34 & 0.00 & 0.57 & 0.00 \\
\hline & Strong decrease (ref) & -0.35 & & -0.66 & & -0.08 & \\
\hline \multirow[t]{3}{*}{ Appearance } & Unchanged & -0.05 & 0.16 & 0.14 & 0.00 & -0.58 & 0.00 \\
\hline & Slightly changed & -0.01 & 0.85 & 0.37 & 0.00 & 0.34 & 0.00 \\
\hline & Significantly changed (ref) & 0.06 & & -0.51 & & 0.25 & \\
\hline Food intake and & No problems & 0.17 & 0.00 & 0.42 & 0.00 & -0.14 & 0.03 \\
\hline \multirow[t]{2}{*}{ digestion } & Minor problems & -0.01 & 0.89 & 0.21 & 0.00 & -0.52 & 0.00 \\
\hline & Strong problems (ref) & -0.17 & & -0.63 & & 0.66 & \\
\hline \multirow[t]{3}{*}{ Waiting time } & None & -0.18 & 0.00 & -0.04 & 0.25 & 0.04 & 0.52 \\
\hline & Moderate & 0.02 & 0.51 & 0.29 & 0.00 & -0.20 & 0.00 \\
\hline & Long (ref) & 0.16 & & -0.26 & & 0.16 & \\
\hline \multirow[t]{2}{*}{ Guide } & Yes & -0.03 & 0.21 & 0.22 & 0.00 & 0.07 & 0.14 \\
\hline & No (ref) & 0.03 & & -0.22 & 0.04 & -0.07 & 0.31 \\
\hline
\end{tabular}

Notes: Age (standardized), sex, cancer type, HRQoL, disease duration (centered by mean), radiation therapy, and change of appearance are used as class membership effects. Abbreviations: cl, class; HRQoL, health-related quality of life; ne, not estimated; ref, reference. 
Table 4 Class-membership effects of latent class mixed logit models (reference: Class 3)

\begin{tabular}{|c|c|c|c|c|c|c|}
\hline \multirow{2}{*}{$\begin{array}{l}\text { Fixed-effects class-membership } \\
\text { model }\end{array}$} & \multicolumn{3}{|l|}{ Class I } & \multicolumn{3}{|l|}{ Class 2} \\
\hline & Coefficient & $\begin{array}{l}\text { Standard } \\
\text { error }\end{array}$ & $P$-value & Coefficient & $\begin{array}{l}\text { Standard } \\
\text { error }\end{array}$ & $P$-value \\
\hline Intercept & 2.609 & 1.380 & 0.059 & $\mathrm{I} .875$ & 1.368 & 0.171 \\
\hline Age (mean centered) & 0.021 & 0.029 & 0.485 & 0.035 & 0.029 & 0.226 \\
\hline Sex $(r e f=$ male $)$ & -1.003 & 0.728 & 0.168 & -0.497 & 0.714 & 0.486 \\
\hline CRC $($ ref $=$ LC) & -2.214 & 0.786 & 0.005 & -1.686 & 0.757 & 0.026 \\
\hline Both cancers $($ ref $=\mathrm{LC})$ & -2.074 & 2.008 & 0.301 & -1.790 & 2.021 & 0.376 \\
\hline HRQoL (mean centered) & -0.537 & 0.267 & 0.044 & -0.403 & 0.263 & 0.125 \\
\hline Disease duration (mean centered) & 0.000 & 0.069 & 0.998 & -0.037 & 0.072 & 0.609 \\
\hline Surgery $($ ref $=$ no $)$ & 1.997 & 0.796 & 0.012 & 1.701 & 0.778 & 0.029 \\
\hline Radiation $($ ref $=$ no $)$ & -1.069 & 0.691 & 0.122 & -0.796 & 0.678 & 0.241 \\
\hline Changes in appearance $($ ref $=$ no) & -0.322 & 0.336 & 0.338 & -0.372 & 0.332 & 0.263 \\
\hline Information: physician & 2.575 & 0.784 & 0.001 & 2.714 & 0.738 & 0.000 \\
\hline
\end{tabular}

Note: Significant values are shown in bold.

Abbreviations: CRC, colorectal cancer; HRQoL, health-related quality of life; LC, lung cancer; ref, reference.

disfavored the most favorable levels of the attributes "physical capacity", "appearance", and "food intake problems" $\left(\beta_{\mathrm{cl} 3, \mathrm{PC} 0}=-0.49, \beta_{\mathrm{cl} 3, \mathrm{AP} 0}=-0.58, \beta_{\mathrm{cl} 3, \mathrm{FI} 0}=-0.14, \beta_{\mathrm{cl} 3, \mathrm{FI} 1}=-0.52\right.$ $P<0.05)$. However, they gave a greater weight to the middle levels for "physical capacity" and "appearance" than to the other levels.

Next, we investigated the class-membership effects for the three classes. Of all the patients, $42.13 \%$ were assigned to Class $1,47.24 \%$ to Class 2, and $10.63 \%$ to Class 3 . The differences between classes 1 and 2 (referenced against Class 3 ) are presented in Table 4. Patients in classes 1 and 2 did not differ significantly from patients in Class 3 in terms of age, sex, or duration of disease. Classes 1 and 2 had a lower proportion of patients with CRC than Class $3\left(\beta_{\mathrm{cl} 1, \mathrm{CRC}}=-2.21\right.$, $\left.\beta_{\mathrm{cl} 2, \mathrm{CRC}}=-1.69 ; P<0.05\right)$. The classes also differed in terms of their therapy experiences: patients in Class 1 were more likely to have undergone surgery than those in classes 2 and 3 ( $\left.\beta_{\text {c11,treat_1 }}=1.997, \beta_{\text {c12,treat_1 }}=1.7 ; P<0.05\right)$. We also observed a difference between the classes with regard to the main source of information on their disease. Patients in classes 1 and 2 were more likely to obtain relevant information from their physician than patients in Class 3 $\left(\beta_{\text {cl1,info_ } 1}=2.58, \beta_{\text {cl2, info_1 }}=2.71 ; P<0.05\right)$. Other sources of information (other patients, books, the Internet, self-help groups) were shown to have no significant influence on the model. In addition, patients in Class 1 showed significantly worse HRQoL outcomes $\left(\beta_{\text {cl1,LQ_30_s }}=-0.54, P=0.04\right)$ than patients in the other classes.

\section{Discussion}

We systematically investigated the differences in the therapy preferences of patients with two divergent types of cancer. Whereas previous studies have examined the therapy preferences of patients with different disease states of the same cancer type, we compared the preferences of patients with CRC and LC. In our first model (mixed logit model), we found that patients with LC and CRC had almost the same preferences for therapy attributes and differed only slightly in their preferences. In the strictly data-driven LCMLM, we found that cancer type, current HRQoL status, and the source of information were important for the therapy preferences.

Subsequently, we will compare our findings in detail with the current knowledge. In accordance with other studies that examined the therapy preferences of patients with LC, "life expectancy" was the most important attribute. . 11,30-32 $^{2}$ This might be due to the shorter life expectancy of patients with LC compared with that of patients with CRC. Another important attribute identified in previous studies was "tumorassociated symptoms". ${ }^{30}$ However, previous studies are quite inconsistent in terms of what they consider to be the chief adverse effect of cancer treatment. For example, one study identified fatigue and tiredness as the two attributes of most consequence, whereas another found that the most consequential attributes were nausea and vomiting..$^{30,31}$ Both assessed the preferences of patients with (advanced) non-small cell LC, which might have strongly influenced the overall results. In our study, we found that "slightly changed appearance" and "no problems in food intake and digestion" were the attribute levels related to adverse effects that were given the greatest weight by patients with CRC and LC, respectively. This might be explained by the fact that patients with CRC expect to experience disturbances of food intake and digestion.

Few studies have found that sociodemographic characteristics, such as sex or age, do not influence preferences for cancer therapy. ${ }^{9,30,33}$ Other studies have reported that sociodemographic characteristics do influence the preferences of patients, but they did not include associations 
between therapy preferences and the actual health status of patients. $^{34,35}$ Two previous studies did not find a difference in preference based on patients' proximity to death. ${ }^{32,34,35}$ However, we observed that having undergone surgery had a noticeable influence on patients' preferences. Therapeutic guidelines recommend surgery at an early disease stage in patients with comorbidities (when the tumor is operable). Therefore, we can assume that patients with a poor prognosis due to LC and a low HRQoL would prefer to increase their length of life when the disease is detected early and surgery is an option.

In summary, our study yielded several novel findings. Patients who were better informed tended to prefer a more balanced relationship between length and quality of life, as compared with less-informed patients. The physicians involved in our study confirmed that they emphasized not only length of life, but also HRQoL as important considerations in their consultations with patients. The influence of physicians on the preferences of patients should be examined in further research. The second finding was that another subgroup (patients with LC and a low HRQoL who had undergone surgery) gave a great weight to increased length of life. Finally, we deduced from patients in Class 3 that those with a relatively good life expectancy (CRC compared with LC) gave a greater weight to moderate effects on HRQoL (physical capacity, appearance) than to a longer life.

However, our study was limited in terms of the unbalanced distribution of patients between the subgroups, which resulted in a small number of patients in Class 3, even though the recruitment period was extended. Furthermore, the results suggest that the online survey was inappropriate for some patients with CRC and LC, particularly patients of advanced age. Alternatively, inappropriate online distributors were used for this process of recruiting older patients. Overall, it appears that older patients were less willing to participate in our study than younger ones. Recruiting patients with LC and CRC at clinics or hospitals might also have biased the study sample, because patients who were not undergoing therapy were excluded. Given that patients were often unaware of their current disease stage or type of chemotherapy (palliative, adjuvant, maintenance), we were unable to include questions concerning this information. It might be possible to estimate disease stage on the basis of self-assessed health and surgery status, although the results can be incomplete or misleading. ${ }^{36-40}$ In addition, surgery can be initiated at different disease stages, such as after diagnosis or in the case of disease progression. This means that the "treatment" variable should not be interpreted without further information. Consequently, future studies should obtain patient records to identify any possible associations between stage, therapy goals, and therapy preferences. Although we defined each attribute at the beginning of the questionnaire, we could not control for how patients interpreted the attributes and levels in their own way and as a result of their own disease experiences. However, we would have detected other results if other or further attributes had been included in the DCE tasks. This disadvantage of the DCE method is also discussed in other methodologic publications. ${ }^{18,41}$

The classes identified by LCMLM cannot be accounted for by typical sociodemographic aspects. Therapy should be adjusted to accommodate these three classes. Some classspecific preferences might be accommodated easily (the provision of a guide or shorter waiting times) and might compensate for some of the disadvantages of chemotherapy. Consequently, differences among the classes should be recognized in individual treatment options. This implies that physicians need time to explain and discuss the therapy alternatives with patients. Our findings can be used to develop treatment guidelines and to assess the benefits of pharmaceuticals. However, in accordance with previous studies, the ability to prolong their survival was the most important therapy attribute of a given therapy for patients, irrespective of the cancer type.

\section{Acknowledgments}

The authors would like to thank all of the patients who participated in the survey. They would also like to thank the physicians and (study) nurses for recruiting the patients, especially: PD Dr med. Heiko Golpon, Annette Nocon (Hannover Medical School: Department of Pneumology), Prof Dr med. Arndt Vogel and team (Hannover Medical School: Department of Gastroenterology, Hepatology and Endocrinology, Hannover, Germany), Dr med. Parvis Sadjadian (Johannes Wesling Medical Center, Department of Hematology, Oncology, Hemostaseology, and Palliative Care UKRUB, University of Bochum, Minden), Dr med. Monika Heilmann and Mrs J Brandes (Lung Cancer Center at the Hospital Region Hannover), Dr rer. nat. Silvia Wagner and Dr med. Silke Templin (Clinic for Visceral, General and Transplant Surgery Surgical Study Center, University Hospital Tuebingen), Dr med. Michael Gärtner and his team (Ambulatory Oncological Center Hannover), Dr med. Raack and Gabriele Germann (Group Practice for Internal Medicine and Pulmonology, Celle), PD Dr med. Annalen Bleckmann (Interdisciplinary Short-term Oncology, Department of 
Hematology and Medical Oncology, Goettingen), Dr med. Detlev Schröder and the study nurse Annette Gieseke (Group Practice for Hematology and Oncology, Hannover).

This study was supported by the Federal Ministry of Education and Research (grant number 01EH1201A).

\section{Author contributions}

All authors contributed toward data analysis, drafting and revising the paper and agree to be accountable for all aspects of the work.

\section{Disclosure}

The authors report no conflicts of interest in this work.

\section{References}

1. Ferlay J, Soerjomataram I, Dikshit R, et al. Cancer incidence and mortality worldwide: sources, methods and major patterns in GLOBOCAN 2012. Int J Cancer. 2015;136(5):E359-E386.

2. Allemani C, Weir HK, Carreira H, et al; CONCORD Working Group. Global surveillance of cancer survival 1995-2009: analysis of individual data for 25676887 patients from 279 population-based registries in 67 countries (CONCORD-2). Lancet. 2015;385(9972): 977-1010.

3. World Health Organization. Global Action Plan for the Prevention and Control of NCDs 2013-2020. Available from: http://apps.who.int/iris/ bitstream/10665/94384/1/9789241506236_eng.pdf?ua=1. Accessed May 26, 2016.

4. Pieterse AH, Baas-Thijssen MCM, Marijnen CAM, Stiggelbout AM. Clinician and cancer patient views on patient participation in treatment decision-making: a quantitative and qualitative exploration. Br J Cancer. 2008;99(6):875-882.

5. Pieterse AH, Stiggelbout AM, Baas-Thijssen MC, van de Velde CJ, Marijnen CA. Benefit from preoperative radiotherapy in rectal cancer treatment: disease-free patients' and oncologists' preferences. Br J Cancer. 2007;97(6):717-724.

6. Harrison JD, Solomon MJ, Young JM, et al. Patient and physician preferences for surgical and adjuvant treatment options for rectal cancer. Arch Surg. 2008;143(4):389-394.

7. Chu DT, Kim SW, Kuo HP, et al. Patient attitudes towards chemotherapy as assessed by patient versus physician: a prospective observational study in advanced non-small cell lung cancer. Lung Cancer. 2007; 56(3):433-443.

8. Solomon MJ, Pager CK, Keshava A, et al. What do patients want? Patient preferences and surrogate decision making in the treatment of colorectal cancer. Dis Colon Rectum. 2003;46(10):1351-1357.

9. Mühlbacher AC, Nübling M. Analysis of physicians' perspectives versus patients' preferences: direct assessment and discrete choice experiments in the therapy of multiple myeloma. Eur J Health Econo. 2011;12(3):193-203.

10. Damm K, Vogel A, Prenzler A. Preferences of colorectal cancer patients for treatment and decision-making: a systematic literature review. Eur J Cancer Care. 2014;23(6):762-772.

11. Schmidt K, Damm K, Prenzler A, Golpon H, Welte T. Preferences of lung cancer patients for treatment and decision-making: a systematic literature review. Eur J Cancer Care. 2015;25(4):580-591.

12. Chue $P$. The relationship between patient satisfaction and treatment outcomes in schizophrenia. J Psychopharmacol. 2006;20(Suppl 6): $38-56$.

13. Casado JL, Marín A, Romero V, et al. The influence of patient beliefs and treatment satisfaction on the discontinuation of current first-line antiretroviral regimens. HIV Med. 2016;17(1):46-55.
14. Hann D, Allen S, Ciambrone D, Shah A. Use of complementary therapies during chemotherapy: influence of patients' satisfaction with treatment decision making and the treating oncologist. Integr Cancer Ther. 2006;5(3):224-231.

15. Federal Ministry of Health. The act on the reform of the market for medicinal products (Gesetz zur Neuordnung des Arzneimittelmarktes - AMNOG); 2011. Available from: https://www.bgbl.de/xaver/ bgbl/start.xav?startbk=Bundesanzeiger_BGBl\&bk=Bundesanzeiger_ BGBl\&start=//*[@attr_id=\%27bgbl110s2262.pdf\%27]. Accessed August 6, 2017.

16. Staeck F. Lebensqualität. Forscher und GBA wollen MethodenSicherheit. Available from: http://www.aerztezeitung.de/politik_ gesellschaft/arzneimittelpolitik/nutzenbewertung/article/925499/ lebensqualitaet-forscher-gba-wollen-methoden-sicherheit.html. Accessed July 05, 2017.

17. Lancsar E, Louviere J. Conducting discrete choice experiments to inform healthcare decision making: a user's guide. Pharmaco Economics. 2008;26(8):661-677.

18. Mühlbacher A, Johnson FR. Choice experiments to quantify preferences for health and healthcare: state of the practice. Appl Health Econ Health Policy. 2016;14(3):253-266.

19. Aumann I, Kreis K, Damm K, Golpon H, Welte T, Graf von der Schulenburg JM. Treatment-related experiences and preferences of patients with lung cancer: a qualitative analysis. Health Expect. 2015; 19(6):1226-1236

20. Auspurg K, Liebe U. Choice-Experimente und die Messung von Handlungsentscheidungen in der Soziologie [Choice-experiments and the measurement of behavioral decisions in sociology]. Köln Z Soziol. 2011; 63(2):301-314. German.

21. Kuhfeld WF. Marketing research methods in SAS. Experimental design, choice, conjoint, and graphical techniques. Available from: http://support.sas.com/techsup/technote/mr2010.pdf. Accessed March 31, 2014

22. Aaronson NK, Ahmedzai S, Bergman B, et al. The European Organization for Research and Treatment of Cancer QLQ-C30: a quality-of-life instrument for use in international clinical trials in oncology. J Natl Cancer Inst. 1993;85(5):365-376.

23. Waldmann A, Schubert D, Katalinic A, Janda M. Normative data of the EORTC QLQ-C30 for the German Population: a population-based survey. PLoS One. 2013;8(9):e74149.

24. de Bekker-Grob, Esther W, Donkers B, Jonker MF, Stolk EA. Sample size requirements for discrete-choice experiments in healthcare: a practical guide. Patient. 2015;8(5):373-384.

25. European Organisation for Research and Treatment of Cancer (EORTC). EORTC QLQ-C30 Scoring Manual. Available from: http://www.eortc.be/qol/files/SCManualQLQ-C30.pdf. Accessed January 11, 2017.

26. Hauber AB, Gonzalez JM, Groothuis-Oudshoorn CGM, et al. Statistical methods for the analysis of discrete choice experiments: a report of the ISPOR conjoint analysis good research practices task force. Value Health. 2016;19(4):300-315.

27. McCulloch CE, Lin H, Slate EH, Turnbull BW. Discovering subpopulation structure with latent class mixed models. Stat Med. 2002; 21(3):417-429.

28. Zentrum für Krebsregisterdaten, Robert Koch Institut. Darmkrebs [Colon and rectum]. Available from: http://www.krebsdaten.de/Krebs/EN/Content/Publications/Cancer_in_Germany/cancer_chapters_2011_2012/ cancer_c18-21.pdf?_blob=publicationFile. Accessed July 26, 2016. German.

29. Zentrum für Krebsregisterdaten, Robert Koch Institut. Lungenkrebs [Lung]. Available from: http://www.krebsdaten.de/Krebs/EN/Content/Publications/Cancer_in_Germany/cancer_chapters_2011_2012/ cancer_c33-34.pdf?__blob=publicationFile. Accessed July 26, 2016. German.

30. Mühlbacher AC, Bethge S. Patients' preferences: a discrete-choice experiment for treatment of non-small-cell lung cancer. Eur J Health Econ. 2015;16(6):657-670. 
31. Bridges JF, Mohamed AF, Finnern HW, Woehl A, Hauber AB. Patients' preferences for treatment outcomes for advanced non-small cell lung cancer: a conjoint analysis. Lung Cancer. 2012;77(1):224-231.

32. Kool M, van der Sijp, Joost RM, Kroep JR, et al. Importance of patient reported outcome measures versus clinical outcomes for breast cancer patients evaluation on quality of care. Breast. 2016;27:62-68.

33. Laryionava K, Sklenarova H, Heußner P, et al. Cancer patients' preferences for quantity or quality of life: German Translation and validation of the quality and quantity questionnaire. Oncol Res Treat. 2014;37(9): $472-478$.

34. Wright AA, Mack JW, Kritek PA, et al. Influence of patients' preferences and treatment site on cancer patients' end-of-life care. Cancer. 2010; 116(19):4656-4663.

35. Stiggelbout AM, de Haes, J C, Kiebert GM, Kievit J, Leer JW. Tradeoffs between quality and quantity of life: development of the QQ Questionnaire for Cancer Patient Attitudes. Med Decis Making. 1996;16(2):184-192.

36. Goeckenjan G, Sitter H, Thomas M, et al. Prevention, diagnosis, therapy, and follow-up of lung cancer: interdisciplinary guideline of the German Respiratory Society and the German Cancer Society. Pneumologie. 2010;64(Supp1 2):e1-e164.
37. German Guideline Program in Oncology. German Cancer Society, German Cancer Aid editors. Evidenced-Based Guideline for Colorectal Cancer. Available from http://www.awmf.org/fileadmin/user_upload/Leitlinien/021_D_Ges_fuer_Verdauungs-_und_ Stoffwechselkrankheiten/021-007_S3_Colorectal_Cancer_2015_03extended.pdf. Accessed August 8, 2017.

38. Polanski J, Jankowska-Polanska B, Rosinczuk J, Chabowski M, Szymanska-Chabowska A. Quality of life of patients with lung cancer. Onco Targets Ther. 2016;9:1023-1028.

39. Adams SV, Ceballos R, Newcomb PA. Quality of life and mortality of long-term colorectal cancer survivors in the seattle colorectal cancer family registry. PLoS One. 2016;11(6):e0156534.

40. Marventano S, Forjaz M, Grosso G, et al. Health related quality of life in colorectal cancer patients: state of the art. BMC Surgery. 2013; 13(Suppl 2):S15.

41. Coast J, Al-Janabi H, Sutton EJ, et al. Using qualitative methods for attribute development for discrete choice experiments: issues and recommendations. Health Econ. 2012;21(6):730-741.

\section{Publish your work in this journal}

Patient Preference and Adherence is an international, peer-reviewed, open access journal that focuses on the growing importance of patient preference and adherence throughout the therapeutic continuum. Patient satisfaction, acceptability, quality of life, compliance, persistence and their role in developing new therapeutic modalities and compounds to optimize clinical outcomes for existing disease states are major areas of interest for the journal. This journal has been accepted for indexing on PubMed Central. The manuscript management system is completely online and includes a very quick and fair peer-review system, which is all easy to use. Visit http://www dovepress.com/testimonials.php to read real quotes from published authors. 